2004

\title{
Red light regulation of ethylene biosynthesis and gravitropism in etiolated pea stems
}

\author{
C. L. Steed \\ L. K. Taylor \\ Marcia Harrison-Pitaniello PhD \\ Marshall University, harrison@marshall.edu
}

Follow this and additional works at: http://mds.marshall.edu/bio_sciences_faculty

Part of the Biology Commons

\section{Recommended Citation}

Steed CL, Taylor LK, Harrison MA. Red light regulation of ethylene biosynthesis and gravitropism in etiolated pea stems. Plant Growth Regulation. 2004;43(2):117-25.

This Article is brought to you for free and open access by the Biological Sciences at Marshall Digital Scholar. It has been accepted for inclusion in Biological Sciences Faculty Research by an authorized administrator of Marshall Digital Scholar. For more information, please contact zhangj@marshall.edu, martj@marshall.edu. 
Running head: ethylene and stem gravitropism in peas

$\underline{\text { Article Type: }}$ general paper

Title: Red light regulation of ethylene biosynthesis and gravitropism in etiolated pea stems Authors: C. L. Steed, L. K. Taylor, and M. A. Harrison

Affiliation: Dept of Biological Sciences, Marshall University, Huntington, WV 25755 USA

Corresponding Author:

Marcia A. Harrison

Dept of Biological Sciences,

Marshall University,

Huntington, WV 25755

USA

Phone: (304) 696-4867

Fax: (304) 696-7136

e-mail: harrison@marshall.edu

Keywords: 1-aminocyclopropane-1-carboxylic acid (ACC), ACC synthase, ACC oxidase, ethylene, gravitropism, red-light 


\section{Abstract}

Harrison-Marshall University

During gravitropism, the accumulation of auxin in the lower side of the stem causes increased growth and the subsequence curvature, while the gaseous hormone ethylene plays a modulating role in regulating the kinetics of growth asymmetries. Light also contributes to the control of gravitropic curvature, potentially through its interaction with ethylene biosynthesis. In this study, red-light pulse treatment of etiolated pea epicotyls was evaluated for its effect on ethylene biosynthesis during gravitropic curvature. Ethylene biosynthesis analysis included measurements of ethylene; the ethylene precursor 1-aminocyclopropane-1-carboxylic acid (ACC); malonylconjugated ACC (MACC); and expression levels of pea ACC oxidase (Ps-ACO1) and ACC synthases ( $P s-A C S 1, P s-A C S 2)$ genes by reverse transcriptase-polymerase chain reaction analysis. Red-pulsed seedlings were given a 6 min pulse of $11 \mu \mathrm{mol} \mathrm{m}^{-2} \mathrm{~s}^{-1}$ red light 15 hours prior to horizontal reorientation for consistency with the timeline of red-light inhibition of ethylene production. Red-pulse treatment significantly reduced ethylene production and MACC levels in epicotyl tissue. However, there was no effect of red-pulse treatment on ACC level, or expression of ACS or ACO genes. During gravitropic curvature, ethylene production increased from 60-120 min after horizontal placement in both control and red-pulsed epicotyls. In redpulsed tissues, ACC levels increased by 120 min after horizontal reorientation, accompanied by decreased MACC levels in the lower portion of the epicotyl. Overall, our results demonstrate that ethylene production in etiolated epicotyls increases after the initiation of curvature. This ethylene increase may inhibit cell growth in the lower portion of the epicotyl and contribute to tip straightening and reduced of overall curvature observed after the initial 60 min of curvature in etiolated pea epicotyls. 
Harrison-Marshall University Abbreviations: AdoMet, S-adenosyl-methionine; ACC, 1-aminocyclopropone-1-carboxylic acid; ACO, ACC oxidase; ACS, ACC synthase; MACC, 1-(malonylamino)cyclopropane1-carboxylic acid; RT-PCR, reverse transcriptase-polymerase chain reaction 


\section{Introduction}

Gravitropism is generally accepted to be controlled by growth-regulating substances and light (Hangarter 1997; Chen et al. 1999; Madlung et al. 1999). The asymmetrical distribution of the plant hormone auxin causes differential growth and upward curvature in stems, while the gaseous hormone ethylene may play a modulating role in regulating the kinetics of the growth asymmetries (Wright et al. 1978; Clifford et al. 1983; Wheeler et al. 1986; Philosoph-Hadas et al. 1996; Madlung et al. 1999). Decades of research on ethylene's involvement in gravitropism reveal that ethylene levels increase in some tissues after a change in a plant's orientation to gravity (Abeles and Rubinstein 1964; Wright et al. 1978; Clifford et al. 1983; Wheeler et al. 1986; Friedman et al. 1998; Philosoph-Hadas et al. 1996), while other research shows no change in ethylene synthesis after reorientation (Harrison and Pickard 1986). Some evidence supports the formation of an ethylene gradient in stem tissue during curvature, with increased ethylene on the lower flank of a horizontal stem (Wheeler et al. 1986; Philosoph-Hadas et al. 1996). In most of these studies, the significant ethylene increase occurs after the onset of the initial upward bending, and thus is considered a modulator of the response rather than a regulator of the initial curvature (Wright et al. 1978; Clifford et al. 1983; Madlung et al. 1999). Studies using exogenously applied ethylene show that higher levels inhibit curvature (Kang and Burg 1972; Harrison and Pickard 1985; Harrison and Pickard 1986; Madlung et al. 1999) or redirect the angle of curvature (Burg and Kang 1993).

Ethylene is produced by the oxidation of 1-aminocyclopropane-1-carboxylic acid (ACC), which is formed from S-adenosyl-methionine (AdoMet) (Adams and Yang 1979; Yang and Hoffman 1984). ACC synthase (ACS) converts AdoMet to ACC, which is oxidized to ethylene 
by ACC oxidase (ACO). The regulation of ACS is considered to serve as the rate-controlling step in ethylene biosynthesis (Wang et al. 2002). Both ACS and ACO enzymes are encoded by gene families whose expression is differentially regulated in various tissues, after hormone application, and by physiological events such as wounding, fruit ripening (Imaseki et al. 1990; Yang et al. 1990; Hyodo et al. 1993), and maintenance of the apical hook formed in shoots of dicotylendonous plants during germination (Schierle and Schwark 1988; Peck et al. 1998). In addition to being the precursor to ethylene, ACC can also be metabolized into its stable conjugate 1-(malonylamino)cyclopropane-1-carboxylic acid (MACC) (Yang 1987). In dark-grown seedlings, red-light reduction of ethylene biosynthesis has been found to cause an increase in MACC content, reducing ACC levels within $2 \mathrm{~h}$ after exposure (Jiao et al. 1987; Vangronsveld et al. 1988). In contrast, during circadian-regulated ethylene production in light-grown cotton, changes in ACC and MACC levels did not parallel the changes in ethylene production, suggesting that ACO controls the rate of ethylene production in this system (Jasoni et al. 2002).

Gravitropic curvature in etiolated stems exhibits an early, linear, upward curvature in the apical region followed by a basal migration of curvature and simultaneous straightening of the tip, resulting in net slowing of curvature (Firn and Digby 1979; Britz and Galston 1982; MacDonald et al. 1983; Pickard 1985; Edelmann 1997; Madlung et al. 1999). Red-light pulse treatment alters the kinetics of gravitropic curvature, shifting the curvature to a sharply localized, more basal zone along the stem (Britz and Galston 1982; Harrison and Pickard 1985; Pickard 1985). Red light treatment also shifts the elongation pattern in etiolated stems from apical localization to a relatively even distribution along the stem (Britz and Galston 1982; Shinkle et al. 1992) with the locus of curvature occurring in more basal tissue. This effect may be due to the red-light induced 
transient reduction in ethylene production seen in tissue from etiolated seedlings, and since this effect is reversible by far-red irradiation, a phytochrome response is suggested (Goeschl et al. 1967; Kang and Burg 1972; Jiao et al. 1987; Vangronsveld et al. 1988). Exogenous ethylene applied to red-pulsed pea epicotyls decreases initial curvature, generating kinetics resembling those of dark-grown seedlings, while reducing ethylene biosynthesis in the dark-grown plants with the inhibitor 1-aminovinylglycine mimics the curvature kinetics of red-pulsed seedlings (Harrison and Pickard 1985). Collectively these data support a role for red-light inhibition of ethylene production in regulating the kinetics of gravitropic curvature of plant stems.

The objective of this research was to examine the role of red-light pulse treatment in regulating ethylene biosynthesis during the initial $2 \mathrm{~h}$ of gravitropic curvature in etiolated pea epicotyls.

\section{Materials and methods}

\section{Plant material and growth conditions.}

Experiments were carried out on 7-day-old etiolated pea seedlings (Pisum sativum L. cv. Alaska). Seeds were sterilized for $10 \mathrm{~min}$ in $0.5 \% \mathrm{v} / \mathrm{v} \mathrm{NaOCl}(10 \% \mathrm{v} / \mathrm{v}$ commercial bleach), rinsed under running tap water for $10 \mathrm{~min}$, then soaked in distilled water for 2-4 h. Seeds were sown in flats $(52 \times 26 \times 6 \mathrm{~cm})$ of vermiculite, and grown in darkness in an environmental chamber (Rheem Scientific, Ashville, NC, USA) at a constant temperature of $23^{\circ} \mathrm{C}$. After germination, all seedlings were watered daily under a dim green light from a 22-W white fluorescent tube (GE Bright Stik®) wrapped with four layers each of both commercial yellow and green cellophane so 
that it produced a fluence rate of $<1 \mu \mathrm{mol} \mathrm{m} \mathrm{m}^{-2}$ with a wavelength range of 520-555 $\mathrm{nm}$. For red-light treatment, a pulse of illumination from two 22-W white fluorescent tubes (GE Bright Stik®) wrapped in three layers of commercial red cellophane with wavelength cut-off at $610 \mathrm{~nm}$ and fluence of $11 \mu \mathrm{mol} \mathrm{m} \mathrm{m}^{-2} \mathrm{~s}^{-1}$ was administered to etiolated seedlings $15 \mathrm{~h}$ before horizontal placement. Exposures of $6.33 \mathrm{~min}$ were used to produce a total fluence of $4200 \mu \mathrm{mol} \mathrm{m}{ }^{-2}$, equivalent to760 $\mathrm{J} \mathrm{m}^{-2}$. This fluence level causes a significant decrease in ethylene production in etiolated pea (Goeschl et al. 1967) and bean (Vangronsveld et al. 1988) stems that persists for 24 $\mathrm{h}$ after light pulse treatment. Plants were gravistimulated by rotating entire flats of seedlings $90^{\circ}$ so that the epicotyls were positioned horizontally. Samples were taken at time zero and 30-min intervals for a total of $120 \mathrm{~min}$.

In vivo Ethylene measurements.

In vivo ethylene measurements were determined from twelve 2-cm subapical epicotyl sections (approximately 1 gram total weight), following the procedures outlined in Steed and Harrison (1993). For ethylene quantitation, sections were excised under water to minimize tissue wounding (Harrison 1991), briefly blotted with a Kimwipe to remove excess water, and placed into a $2-\mathrm{ml}$ shell vial. The segments were incubated at room temperature for $2 \mathrm{~min}$, sealed with a rubber septum, and analyzed for ethylene accumulation 15 min later. A $1.0 \mathrm{ml}$ headspace sample was injected onto an alumina F1 column (1/4 x $3 \mathrm{ft})$ in a gas chromatograph (Varian 3700, Varian Instrument Division, Walnut Creek, CA, USA) equipped with a flame ionization detector. 
Harrison-Marshall University

This procedure provided basal ethylene measurements prior to the onset of wound-induced ethylene production (Harrison 1991; Harrison 1997). Known amounts of an ethylene standard (Scott Specialty Gases, Plumsteadville, PA, USA) were analyzed to produce a standard curve for ethylene quantitation.

\section{ACC and MACC measurements.}

Stem ACC and MACC levels in both red-pulsed and control seedlings were determined at time zero and at 30-min intervals for the first 120 min of gravitropic curvature. ACC and MACC extraction and quantification followed procedures described previously (Steed and Harrison 1993; Harrison 1997). Approximately $0.5 \mathrm{~g}$ subapical segments (2 cm long) were excised in distilled water, blotted with a Kimwipe, homogenized with a mortar and pestle in $2 \mathrm{ml}$ boiling $80 \%$ (v/v) ethanol, and centrifuged for $10 \mathrm{~min}$ at 10,000 $\mathrm{g}$ in a Sorvall RC-5B Refrigerated Superspeed centrifuge (Dupont Co., Wilmington, CT, USA). For studies comparing the upper and lower tissue of gravistimulated seedlings, the curving portion of the subapical stem segments was cut lengthwise, using approximately $0.25 \mathrm{~g}$ tissue for each upper or lower sample. The supernate was equally divided into 2 samples and concentrated under vacuum (Labconco CentriVap ${ }^{\mathrm{TM}}$, Kansas City, MO, USA) (Riov and Yang 1982a, b). Free ACC was analyzed from one sample of each pair by reacting $600 \mu \mathrm{l}$ rehydrated material with $100 \mu \mathrm{l}$ of $10 \mathrm{mM} \mathrm{HgCl} 2$ to reduce the effects of interfering proteins (Lizada and Yang 1979). Next, $0.1 \mathrm{ml}$ of a 2:1 mixture of saturated $\mathrm{NaOH}$ and $\mathrm{NaOCl}$ was added, followed by a 3-min incubation to allow for total 
hydrolysis of ACC to ethylene, which was measured by gas chromatography as previously described. To determine the amount of conjugated ACC, the second sample of each pair was hydrolyzed in $400 \mu \mathrm{l}$ of $6 \mathrm{~N} \mathrm{HCl}$ for 1 h to release conjugated ACC (Vangronsveld et al. 1988). The sample was then neutralized with $150 \mu \mathrm{l} 13.25 \mathrm{~N} \mathrm{NaOH}$, followed by the addition of $50 \mu \mathrm{l}$ $\mathrm{H}_{2} \mathrm{O}$ and $100 \mu \mathrm{l} 10 \mathrm{mM} \mathrm{HgCl}$ to total a volume of $700 \mu \mathrm{l}$. As with the first set of samples, the saturated $\mathrm{NaOH} / \mathrm{NaOCl}$ mixture was added, the samples were incubated, and ethylene production was measured. For each pair of samples, the ethylene generated by free ACC was subtracted from ethylene generated by the total ACC to determine the final amount of conjugated ACC. This protocol determines endogenous levels of total conjugated ACC, and does not separate MACC from the $\gamma$-glutamyl-conjugated form of ACC (Martin et al. 1995). However, since MACC has been reported to be the sole conjugated form of ACC in etiolated pea epicotyls (Peiser and Yang 1998), it is assumed that this procedure measured only MACC. Quantification of ACC was determined using aliquots of ACC standard (Sigma, St. Louis, MO, USA) subjected to the same procedure as for plant tissue.

ACS and ACO expression analysis.

RT-PCR was used to evaluate the expression changes of two ACC synthases (Ps-ACS1, Ps$A C S 2)$ and ACC oxidase (Ps-ACO1) in both red-light treated and control subapical epicotyl segments $15 \mathrm{~h}$ after light pulse. Total-RNA was extracted with the RNeasy Plant Mini Kit (Qiagen, Valencia, CA, USA) from approximately $100 \mathrm{mg}$ fresh weight epicotyl sections ground in liquid nitrogen. Total-RNA samples were treated with DNase (DNA-Free Kit, Ambion, 
Austin, TX, USA), and quantified according to the RiboGreen RNA Quantitation Kit protocol (Molecular Probes Inc., Eugene, OR, USA). Primers used for amplification were as follows: PsACS1 (accession no. AF016460), 5'-AGCTGGTGCCACTTCTGCTA-3'(forward), and 5'CATGAGCTTGTTGCAAAGCA-3' (reverse); Ps-ACS2 (accession no. AF016459), 5'TTGAATGCGACCGTAACCTC -3'(forward) and 5'-AACCAACCTGGTTCAGAGCA3'(reverse), and Ps-ACO1 (accession no. M98357), 5'-TAGAGCTCACACAGATGCCG-3' (forward) and 5'-GAAATCACAGCATCATCCCC-3' (reverse). Primer design for Ps-ACS1 included sequences that span an intron in order to appraise genomic DNA contamination. A $25 \mu \mathrm{l}$ RT-PCR reaction was performed according to the AccessQuick RT-PCR System (Promega Corp., Madison, WI, USA) protocol (one cycle at $48^{\circ} \mathrm{C}$ for $45 \mathrm{~min}$, one cycle at $94^{\circ} \mathrm{C}$ for $2 \mathrm{~min}$, followed by a variable number of cycles of $94^{\circ} \mathrm{C}$ for $30 \mathrm{sec}, 60^{\circ} \mathrm{C}$ for $1 \mathrm{~min}$, and $68^{\circ} \mathrm{C}$ for 2 min; one extension cycle at $68^{\circ} \mathrm{C}$ for $7 \mathrm{~min}$; and a final $1 \mathrm{~h}$ soak at $4^{\circ} \mathrm{C}$ ) and performed using an iCycler thermal cycler (Bio-Rad Laboratories, Hercules, CA, USA). The reaction mixture was optimized for RNA content and number of cycles in order to determine the following nonsaturating conditions for each transcript: $P s-A C S 1,30$ cycles with $65 \mathrm{ng}$ RNA; Ps-ACS2, 28 cycles with 65 ng RNA; and $P s-A C O 1,30$ cycles with 80 ng RNA. The PCR products were separated by electrophoresis on a $2 \%(\mathrm{w} / \mathrm{v})$ agarose gel and stained with ethidium bromide. Gels were imaged on a GelDoc 2000 (Bio-Rad Laboratories, Hercules, CA, USA) and relative gene expression was determined by band intensity quantified using Quantity One Software (Bio-Rad Laboratories, Hercules, CA, USA). 
Statistical analyses.

Statistical analyses were performed using Microsoft Excel or Jandel Sigma Stat software. $P$ values were determined by t-test. Standard errors of the mean are shown for the data points of each figure. Data was collected from a minimum of five sets of experiments for each study.

\section{Results}

In etiolated pea epicotyls, the red-light pulse significantly $(P=0.004)$ decreased ethylene production by $15 \mathrm{~h}$ after light treatment (zero time point, Figure 1A). Ethylene production rates increased during gravitropic curvature by $60 \mathrm{~min}$ gravistimulation in both red-pulsed $(P=0.025$ at $60 \mathrm{~min}$ ) and control $(P=0.005$ at $60 \mathrm{~min}$ ) epicotyls (Figure 1A), and remained higher than the zero time point from the 60 to 120 min time points for both treatments. Ethylene production in red-pulsed tissue remained significantly lower throughout the 2 -h gravitropic time course relative to control shoots that received only short-term dim green light. Red-pulse treatment did not alter ACC levels $15 \mathrm{~h}$ after treatment (zero time point, Figure 1B). Comparison of ACC levels in control and red-pulsed pea segments revealed no significant differences between the two light treatments at any time point during gravitropic curvature. ACC increased significantly in the redpulsed stems at $90 \min (P=0.05)$ and $120 \min (P=0.01)$ after horizontal reorientation compared to ACC levels at time zero (Figure 1B). However, when ACC levels were investigated in the upper and lower halves of horizontally placed red-pulsed stems, no significant difference 
between the segment halves was found for either 60 or 120 min after horizontal placement (Figure 2).

MACC levels were significantly $(P=0.03)$ higher in control compared to red-pulsed seedlings at the zero time point (Figure 1C). During gravitropic curvature, MACC content in control tissue was significantly lower by the $60(P=0.045)$ and $90(\mathrm{P}=0.016)$ min time points, relative to time zero (Figure 1C). Overall, MACC levels were higher than ACC tissue levels, indicating a high capacity for conjugation in etiolated pea epicotyls. When MACC levels were investigated in the upper and lower halves of horizontally placed red-pulsed stems, MACC levels in the lower halves was significantly lower $(P=0.04)$ compared to the upper halves by $120 \mathrm{~min}$ after horizontal placement (Figure 2).

Red-pulse treatment did not significantly change $P s-A C S 1, P s-A C S 2$, or $P s-A C O 1$ expression levels at the zero time point $(P=0.07,0.24$ and 0.63 , respectively) (Figure 3$)$. This result is also supported by the lack of change in in vivo ACO activity between red-pulsed tissues compared to the controls at any measured time point (data not shown).

\section{Discussion}

In this study, the effects of red light treatment on ethylene biosynthesis parameters were evaluated in the subapical elongation zone of etiolated pea stems during the first $2 \mathrm{~h}$ of gravitropic curvature. Previous studies show that in horizontally-oriented etiolated pea stems, rapid upward gravitropic curvature occurs between 30 and $60 \mathrm{~min}$, followed by basal migration of curvature and simultaneous tip straightening that results in a reduction of curvature by $90 \mathrm{~min}$ after horizontal reorientation (Harrison and Pickard 1985; Pickard 1985). Pea shoots pulsed with 
Harrison-Marshall University red light several hours prior to horizontal placement exhibit a more linear gravitropic response, with less slowing after 90 min, and ultimately achieve greater curvature than shoots exposed only to dim green light pulses (Harrison and Pickard 1985). Our results demonstrate increased ethylene production during gravitropic curvature 60-120 min after horizontal reorientation in both red-pulsed and control epicotyls (Figure 1A). The lower level of ethylene production in redpulsed epicotyls throughout the 2-h gravitropic time course may contribute to the altered growth patterns associated with the kinetics of gravitropism for that tissue. The question remains as to whether ethylene increases because of auxin accumulation in the lower portion of the stem, or whether ethylene is playing an independent role in regulating curvature migration and its net slowing during gravitropism in etiolated stems.

The biosynthetic cause of increased ethylene production during gravitropism has been difficult to determine. Our results demonstrate increased ACC in red-treated tissue by 90 and 120 min of gravitropic curvature (Figure 1B). The increased ACC level in the red-treated tissue is consistent with previous reports showing that increased ethylene during gravitropic curvature is accompanied by higher ACC levels (Abeles et al. 1992; Philosoph-Hadas et al. 1996). However, those changes in ACC do not represent a gradient between the upper and lower halves of stem segments (Figure 2). Additionally, the MACC level is significantly reduced in the lower halves of the red-pulsed tissue by 120 min reorientation (Figure 2). This decrease in conjugation could result in the increased ACC found at 120 min reorientation (Figure 1B).

Our results from etiolated pea epicotyls confirm that a short-term red-light pulse reduces ethylene $15 \mathrm{~h}$ after treatment (zero time point, Figure 1A), consistent with previous reports for etiolated pea (Goeschl et al.1967; Harrison and Pickard 1985), bean (Kang and Ray 1969; Kang 
and Burg 1972; Vangronsveld et al. 1988), and wheat (Jiao et al. 1987) for this level and duration of light pulse. In etiolated seedlings, red-light induced reduction of ethylene production begins at approximately 2-4 h after the pulse and persists for up to $20 \mathrm{~h}$ depending on the redlight dose administered (Goeschl et al. 1967; Kang and Ray 1969; Kang and Burg 1972; Harrison and Pickard 1985; Jiao et al. 1987; Vangronsveld et al. 1988). ). However, RT-PCR analysis of $P s-A C S 1, P s-A C S 2$, and $P s-A C O 1$ expression did not show strong regulation at the transcriptional level (Figure 3). Additionally, our results did not support red-light stimulation of ACO activity (data not shown) as observed in etiolated wheat leaves (Jiao et al. 1987) and for circadian ethylene regulation in cotton (Jasoni et al. 2002). Comparison of the Ps-ACS1 sequence with other ACS genes shows that it is most similar to the auxin-induced mungbean $V r$-ACS6 ( $80 \%$ nucleotide and $85 \%$ amino acid sequence homology). In a recent model for differential $A C S$ regulation in mungbean, $V r-A C S 6$ and $V r-A C S 7$ are auxin-induced, whereas $V r-A C S 1$ is not regulated by auxin, but is suppressed by ethylene in a feedback mechanism that concurrently activates $V r$-ACO1 expression (Kim et al. 2001). This model presents a complex regulation system for the $A C S$ and $A C O$ genes, and most likely accounts for the reported differences in responses for plants grown under different conditions that may alter endogenous hormone levels.

In our study, red-pulsed tissue showed reduced MACC levels relative to green-pulsed tissue 15 $\mathrm{h}$ after pulse treatment (zero time point, Figure 1C), in contrast to previous reports of red-light increased conjugation of ACC to MACC (Jiao et al. 1987, Vangronsveld et al. 1988). Jiao et al. (1987) demonstrated that red-light pulsed etiolated wheat leaves display reduced ethylene and ACC content, accompanied by increased MACC $6 \mathrm{~h}$ after light treatment. While our results do not show a difference in ACC content between red-pulsed and control seedlings, this could be 
Harrison-Marshall University

due to the duration and timing of the red-light pulse and subsequent incubation in darkness.

Since our studies were conducted $15 \mathrm{~h}$ after a single light pulse treatment, the ACC level may be returning to a basal level during that time as the plants reacclimate to dark conditions.

Additionally, Vangronsveld et al. (1988) analyzed whole seedlings, and did not differentiate between ethylene, ACC, and MACC levels in the root as compared to the shoot tissue. It is possible that the stem MACC level was low $15 \mathrm{~h}$ after irradiation because MACC was removed from the stem tissue and transported to the roots as previously reported for peas (Fuhrer and Fuhrer-Fries 1985). Our results appear to be more consistent with the light-dependent changes in circadian ethylene production in cotton plants, in which MACC increases when plants are moved to constant darkness (Jasoni et al. 2002). Our zero time point in control seedlings may represent changes associated with acclimation to continuous darkness. Our study suggests that there are changes in the MACC levels in the upper versus lower halves of red-pulsed reoriented epicotyls during gravitropic curvature (Figure 3). The increase in MACC in the upper halves and decrease in MACC in the lower halves at 120 min reorientation may indicate that ACC may be increasingly conjugated where its activity is not needed, and conjugated to a lesser extent where ACC's conversion to ethylene would modulate the kinetics of the migration of gravitropic curvature. Jasoni et al. (2002) also note dynamic fluctuations of MACC over a $72 \mathrm{~h}$ time period. They conclude that MACC may play an important role in the regulation of ethylene biosynthesis and may be metabolized to ACC or transported to other tissues. This is consistent with previous evidence that under certain conditions the conversion of MACC to ACC may be also be a means of ethylene control (Jiao et al. 1986). Therefore, differences in reported MACC levels could reflect subtle growth and lighting variations between the systems, and our MACC results support 
Harrison-Marshall University

the hypothesis that more dynamic changes in MACC levels are based on these variations.

Differential cell elongation such as that which drives gravitropism has also been associated with differences in invertase activity and invertase transcript levels (Kaufman et al. 1995, Long et al. 2002). Philosoph-Hadas et al. (1996) found that ethylene inhibitors remove the asymmetric soluble invertase in gravistimulated snapdragon spikes. However, our preliminary data show an insignificant decrease in soluble invertase activity with increased ethylene production during gravitropic curvature in etiolated pea epicotyls. This suggests that activation of invertase activity is not a target of the ethylene transduction pathway in this tissue (data not shown).

In summary, our results indicate that a short-term red-light pulse significantly decreases ethylene production in etiolated pea epicotyls, with ethylene production rising after horizontal reorientation. Increased ethylene during gravitropic curvature occurs $60 \mathrm{~min}$ after reorientation. Ethylene may cause localized cellular inhibition that could direct the overall slowing of curvature. The lower ethylene levels produced by the red-pulsed seedlings may contribute to the differences in the curvature kinetics relative to controls, specifically through the regulation of tip straightening. Reduced ethylene production would tend to prevent tip straightening and result in the increased overall curvature seen in the red-pulsed plants. Comparison of the reports on ACC and MACC fluctuations reveals a dynamic nature that does not necessarily predict overall changes in ethylene production or changes in response to light conditions. The decreased ethylene production relative to control tissue does not reflect expression changes for $A C O$ or $A C S$ 15 hours after light treatment. Thus, regulation may also occur post-transcriptionally and be fairly tissue specific. Also, differential regulation of the various $A C S$ genes could be influenced by a variety of factors and feedback mechanisms in response to light and horizontal reorientation. 
Detailed kinetics of red-light regulation of $A C S$ and $A C O$ expression would help elucidate the initial state of the plants prior to reorientation. Additional analyses of expression changes for individual ACS genes during gravitropic curvature may provide evidence for the increased ACC levels observed in the red-pulsed seedlings. Studies using transgenic plants with ACS promoterreporter constructs or in situ RT-PCR would allow the identification and evaluation of localized effects within a tissue after light treatment and during gravitropic curvature. In addition, dissection for the upper and lower sections of epicotyls still produces a fairly large area containing a number of different tissues. As the epicotyl curves, the differential elongation is a summation of basal curvature and simultaneous tip straightening, so that dissection of the tissue into upper and lower halves does not adequately separate the various zones of elongation within the epicotyl. Studies using high-resolution analysis of growth and gravitropic kinetics would elucidate the area of elongation during gravitropic curvature. In roots this techniques reveals a distinct group of motor cells in the distal elongation zone that grow in response to a change in orientation (Ishikawa et al. 1991; Evans and Ishikawa 1997). Such zones distinct from the main elongation zone may also exist in pea epicotyls and may even migrate as curvature progresses. Using an approach similar to that of Ishikawa et al. (1991) along with in situ studies that evaluate more discrete areas of the epicotyl will help identify the changing zones of elongation in the stem during curvature and allow further analysis of the role of ethylene biosynthesis in this process. 
Harrison-Marshall University

Acknowledgments - We thank Susan Weinstein for her careful reading and helpful advice

concerning this manuscript. This research was supported by the National Aeronautics and Space

Administration (NAGW-3859), USDA-NRI (2001-35311-11186), and the NASA-EPSCoR West

Virginia Space Grant Consortium. 


\section{References}

Abeles F.B. and Rubinstein B. 1964. Regulation of ethylene evolution and leaf abscission by auxin. Plant Physiol. 39: 963-969.

Abeles F.B., Morgan P.W. and Saltveit M.E. 1992. Ethylene in Plant Biology, $2^{\text {nd }}$ edition. Academic Press, San Diego, 414 pp.

Adams D.O. and Yang S.F. 1979. Ethylene biosynthesis: identification of 1-aminocyclopropane-1-carboxylic acid as an intermediate in the conversion of methionine to ethylene. Proc. Natl. Acad. Sci. USA 76:170-174.

Britz S.J. and Galston A.W. 1982. Physiology of movements in stems of seedling Pisum sativum L. cv. Alaska. I. Experimental separation of nutation from gravitropism. Plant Physiol. 70: 264-271.

Burg S.P. and Kang B.G. 1993. Gravity dependent ethylene action. In: Peck J.C., Latache A., and Balague C. (eds.), Cellular and Molecular Aspects of the Plant Hormone Ethylene. Kluwer Academic Publishers, Dordrecht, pp. 335-341.

Chen R., Rosen E. and Masson P.H. 1999. Gravitropism in higher plants. Plant Physiol. 120: 343-350.

Clifford P.E., Reid D.M. and Pharis R.P. 1983. Endogenous ethylene does not initiate but may modify geobending-a role for ethylene in autotropism. Plant Cell Environ. 6: 433-436.

Edelmann H.G. 1997. Gravistimulated asymmetries in the outer epidermal cell walls of graviresponding coleoptiles. Planta 203: S123-S129.

Evans M.L. and Ishikawa H. 1997. Cellular specificity of the gravitropic motor response in roots. Planta 203: S115-S122 
Firn R.D. and Digby J. 1979. A study of the autotropic straightening reaction of a shoot previously curved during geotropism. Plant Cell Environ. 2: 149-154.

Friedman H., Meir S., Rosenberger I., Halevy A.H., Kaufman P.B. and Philosoph-Hadas S. 1998. Inhibition of the gravitropic response of snapdragon spikes by the calcium-channel blocker lanthanum chloride. Plant Physiol. 118: 483-492.

Fuhrer J. and Fuhrer-Fries C.B. 1985. Formation and transport of 1-aminocyclopropane-1-carboxylic acid in pea plants. Phytochemistry 24: 19-22.

Goeschl J.D., Pratt H.K. and Bonner B.A. 1967. An effect of light on the production of ethylene and the growth of the plumular portion of etiolated pea seedlings. Plant Physiol. 42:1077-1080.

Hangarter R.P. 1997. Gravity, light and plant form. Plant Cell Environ. 20: 796-800.

Harrison M.A. and Pickard B.G. 1985. Red light shifts the locus and rate of gravitropic curvature in etiolated pea epicotyls. The Physiologist 28 Suppl.: 103-104.

Harrison M.A. and Pickard B.G. 1986. Evaluation of ethylene as a mediator of gravitropism by tomato hypocotyls. Plant Physiol. 80: 592-595.

Harrison M.A. 1991. Evidence of a heat-stress signal in etiolated pea epicotyls. Plant Sci. 75: 1924.

Harrison M.A. 1997. Analysis of Ethylene Biosynthesis. In: Dashek W.V. (ed.), Methods in Plant Biochemistry and Molecular Biology. CRC Press, Boca Raton, pp. 153-164.

Hyodo H., Hashimoto C., Morozumi S., Hu W. and Tanaka K. 1993. Characterization and induction of the activity of 1-aminocyclopropane-1-carboxylate oxidase in the wounded mesocarp tissue of Cucurbita maxima. Plant Cell Physiol. 34: 667-671. 
Imaseki H., Nakajima N., Nikagawa N., Mori H. and Yamazaki K. 1990. Wound induction of 1-aminocyclopropane-1-carboxylate synthase and its regulation. In: Flores H.E., Arteca R.N., and Shannon J.C. (eds.), Polyamines and Ethylene: Biochemistry, Physiology, and Interactions. American Society of Plant Physiologists, Rockville, pp. 180-189.

Ishikawa H., Hasenstein K.H., and Evans M.L. 1991. Computer-based video digitizer analysis of surface extension in maize roots. Kinetics of growth rate changes during gravitropism. Planta 183: $381-390$.

Jasoni R.L., Cothren J.T., Morgan P.W. and Sohan D.E. 2002. Circadian ethylene production in cotton. Plant Growth Regul. 36: 127-133.

Jiao X.Z., Yip W.K. and Yang S.F. 1987. The effect of light and phytochrome on 1-aminocyclopropane-1-carboxylic acid metabolism in etiolated wheat seedling leaves. Plant Physiol. 85: 643-647.

Jiao X.Z., Philosoph-Hadas S., Su L.Y. and Yang S.F 1986. The conversion of 1(malonylamino)cyclopropane-1-carboxylic acid to 1-aminocyclopropane-1-carboxylic acid in plant tissues. Plant Physiol. 81: 637-641.

Kang B.G. and Burg S.P. 1972. Relation of phytochrome-enhanced geotropic sensitivity to ethylene production. Plant Physiol. 50: 132-135.

Kang B.G. and Ray P.M. 1969. Ethylene and carbon dioxide as mediators in the response for the bean hypocotyl hook to light and auxins. Planta 87: 206-216.

Kaufman P.B, Wu L.L., Brock T.G. and Kim D. 1995. Hormones and orientation of growth. In: Davies P.J. (ed.), Plant Hormones: Physiology, Biochemistry and Molecular Biology. Kluwer Academic Publishers, Dordrecht, pp. 547-571. 
Kim J.H., Kim W.T. and Kang B.G. 2001. IAA and $\mathrm{N}^{6}$-benzyladenine inhibit ethylene-regulated expression of ACC oxidase and ACC synthase genes in mungbean hypocotyls. Plant Cell Physiol. 42: 1056-1061.

Lizada M.C.C. and Yang S.F. 1979. A simple and sensitive assay for 1-aminocyclopropane-1carboxylic acid. Anal. Biochem. 100: 140-145.

Long J.C., Zhao W., Rashotte A.M., Muday G.K. and Huber S.C. 2002. Gravity-stimulated changes in auxin and invertase gene expression in maize pulvini cells. Plant Physiol. 128: 591-602.

MacDonald I.R., Hart J.W. and Gordon D.C. 1983. Analysis of growth during geotropic curvature in seedling hypocotyls. Plant Cell Environ. 6: 401-406.

Madlung A., Behringer F.J. and Lomax T.L. 1999. Ethylene plays multiple nonprimary roles in modulating the gravitropic response in tomato. Plant Physiol. 120: 897-906.

Martin M.N., Cohen J.D. and Saftner R.A. 1995. A new 1-aminocyclopropane-1-carboxylic acidconjugating activity in tomato fruit. Plant Physiol. 109: 917-926.

Peck S.C., Pawlowski K. and Kende H. 1998. Asymmetric responsiveness to ethylene mediates cell elongation in the apical hook of peas. Plant Cell 10: 713-719.

Peiser G. and Yang S.F. 1998. Evidence for 1-(malonylamino)cyclopropane-1-carboxylic acid being the major conjugate of aminocyclopropane-1-carboxylic acid in tomato fruit. Plant Physiol. 116: 1527-1532.

Philosoph-Hadas S., Meir S., Rosenberger I. and Halevy A.H. 1996. Regulation of the gravitropic response and ethylene biosynthesis in gravistimulated snapdragon spikes by calcium chelators and ethylene inhibitors. Plant Physiol. 110: 301-310. 
Pickard B.G. 1985. Roles of hormones, protons and calcium in geotropism. In: Pharis R.P. and Reid D.M. (eds.), Encyclopedia of Plant Physiology, New Series Vol 11. Springer-Verlag, Heidelberg, pp. 193-281.

Riov J. and Yang S.F. 1982a. Autoinhibition of ethylene production in citrus peel discs. Suppression of 1-aminocyclopropane-1-carboxylic acid synthesis. Plant Physiol. 69: 687-690.

Riov J. and Yang S.F. 1982b. Effect of exogenous ethylene on ethylene production in citrus leaf tissue. Plant Physiol. 70: 136-141.

Schierle J. and Schwark A. 1988. Asymmetric synthesis and concentrations of ethylene in the hypocotyl hook of Phaseolus vulagaris. J Plant Physiol. 133: 325-331.

Shinkle J.R., Sooudi S.K. and Jones R.L. 1992. Adaptation to dim-red light leads to a nongradient pattern of stem elongation in Cucumis seedlings. Plant Physiol. 99: 808-811.

Steed C.L. and Harrison M.A. 1993. Regulation of ethylene biosynthesis after short-term heat treatment in etiolated pea stems. Physiol. Plantarum 87: 103-107.

Vangronsveld J., Clijsters H. and Van Poucke M. 1988. Phytochrome-controlled ethylene biosynthesis of intact etiolated bean seedlings. Planta 174: 19-24.

Wang K. L.-C., Hai L. and Ecker J. R. 2002. Ethylene biosynthesis and signaling networks. The Plant Cell 14: S131-151.

Wheeler R.M., White R.G. and Salisbury F.B. 1986. Gravitropism in higher plant shoots. IV. Further studies on participation of ethylene. Plant Physiol. 82: 534-542.

Wright M., Mousdale D.M.A. and Osborne D.J. 1978. Evidence for a gravity-regulated level of endogenous auxin controlling cell elongation and ethylene production during geotropic 
bending in grass nodes. Biochem. Physiol. Pflanzen 172: 581-596.

Yang S.F. and Hoffman N.E. 1984. Ethylene biosynthesis and its regulation in higher plants.

Ann. Rev. Plant Physiol. 35: 155-189.

Yang S.F. 1987. The biosynthesis and metabolism of 1-(malonylamino)cyclopropane-1carboxylic acid in relation to ethylene production. In: Schreiber K., Schütte H.R. and Sembdner G. (eds.), Conjugated Plant Hormones: Structure, Metabolism and Function. VEB Deutscher Verlag der Wissenschaften, Berlin, pp. 92-101.

Yang S.F., Yip W.K. and Dong J. 1990. Mechanism and Regulation of Ethylene Biosynthesis. In: Flores H.E., Arteca R.N. and Shannon J.C. (eds.), Polyamines and Ethylene: Biochemistry, Physiology, and Interactions. American Society of Plant Physiologists, Rockville, pp. 24-35. 
Harrison-Marshall University

\section{FIGURES AND FIGURE LEGENDS}
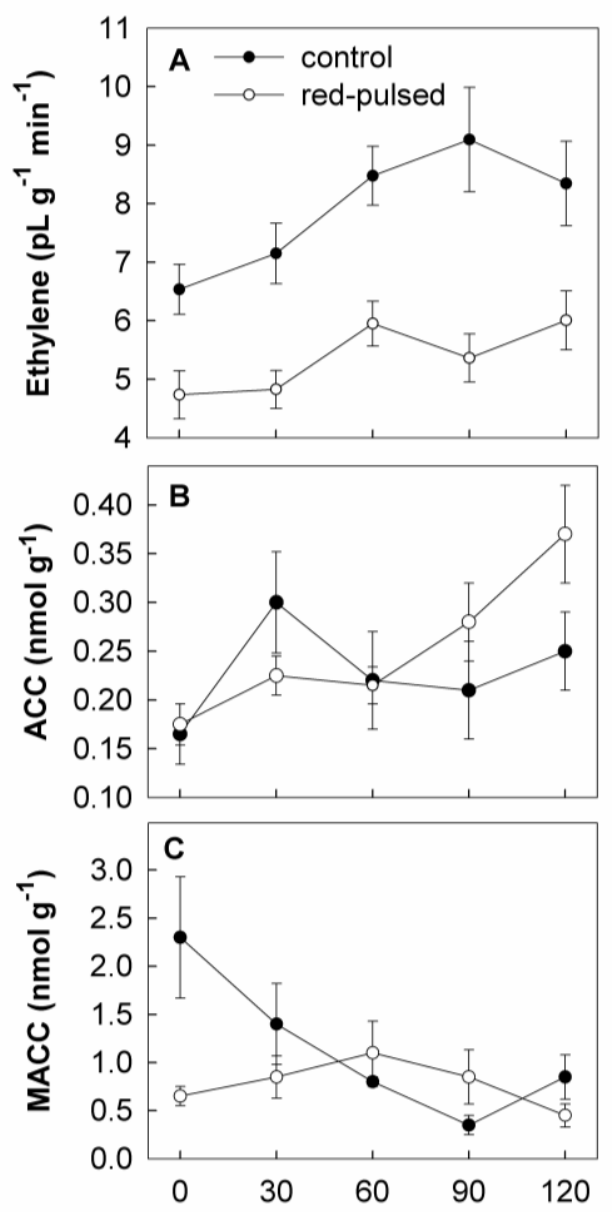

Minutes after horizontal placement

Figure 1. Ethylene production rates (A), ACC (B), and MACC (C) levels in green-pulsed control $(\bullet)$ and red-pulsed (o) etiolated pea epicotyls during gravitropic curvature. After germination, all seedlings were exposed to 3 min dim green light daily. Red-pulse treatment was given to greenpulsed seedlings $15 \mathrm{~h}$ before horizontal placement. Results represent means of a minimum of eight repetitions $\pm \mathrm{SE}$. 
Harrison-Marshall University

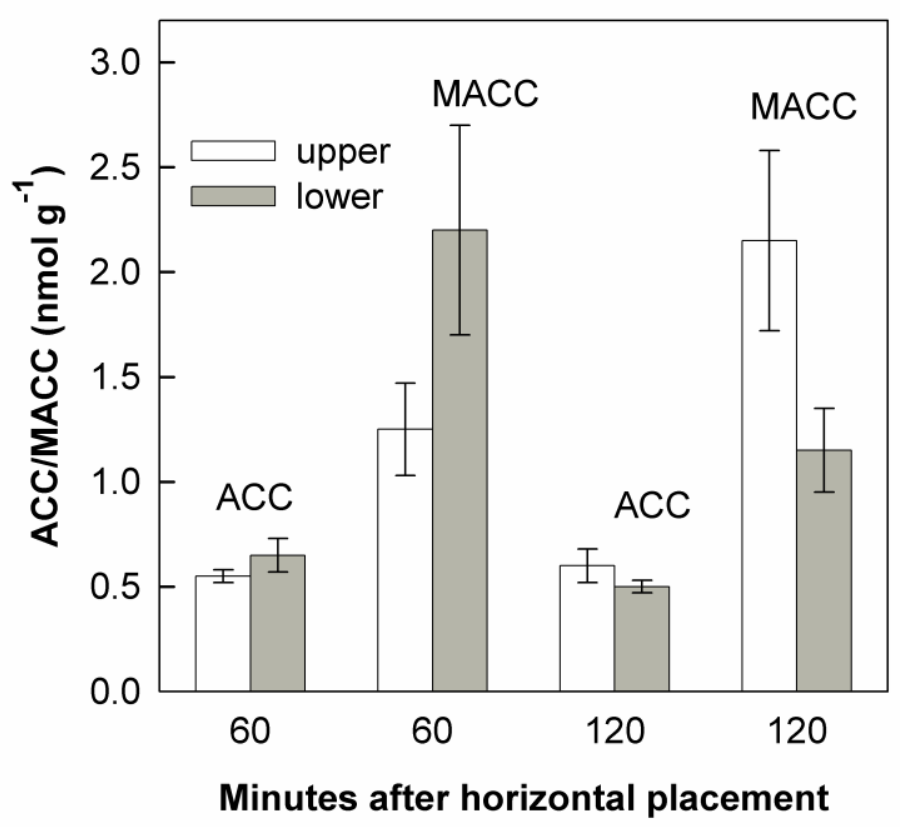

Figure 2. Tissue levels of ACC and MACC in the upper (open bars) and lower (shaded bars) segments of red-pulsed etiolated pea epicotyls at 60 and $120 \mathrm{~min}$ after horizontal reorientation. Results represent means of a minimum of ten repetitions \pm SE. 


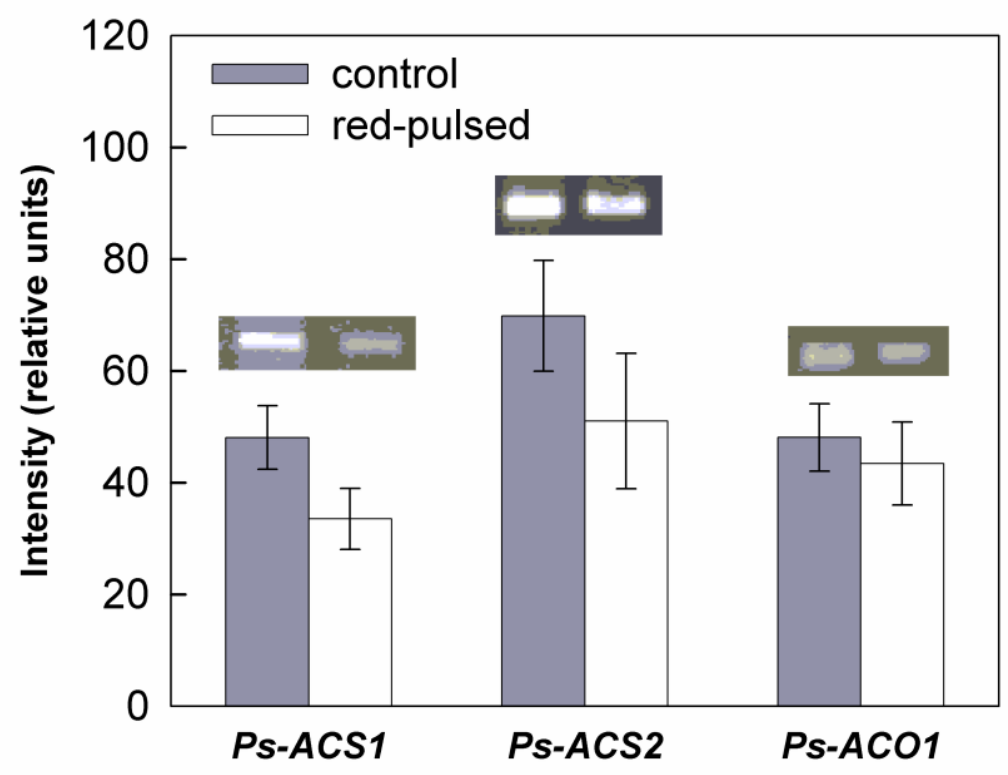

Figure 3. Non-saturating RT-PCR analysis of transcript levels for Ps-ACS1, Ps-ACS2, and Ps$A C O 1$ in subapical epicotyl segments. Total RNA extracted from control seedlings that were exposed to 3 min dim green light daily was compared to seedlings given a red-pulse treatment 15 $\mathrm{h}$ before total RNA extraction at the zero time point. RT-PCR products were separated on a $2 \%$ agarose gel stained with ethidium bromide. Relative intensity levels represent band intensity as a percent of expression of a control gene (tubulin). Data represents averages from five independent experiments. Gels shown are from representative experiments and are positioned above the bars for their respective treatments. 